\title{
Facilitating active learning and enhancing student self-assessment skills
}

Fabio Arico ${ }^{\mathrm{a} *}$ and Simon J. Lancaster ${ }^{\mathrm{b} *}$

aSchool of Economics, 'bchool of Chemistry, University of East Anglia, Norwich Research Park, Norwich, NR4 7TJ. UK.

F.Arico@uea.ac.uk \& S.Lancaster@uea.ac.uk

\section{Keywords}

flipping, active learning, peer instruction, self-assessment.

\section{Graphical abstract}

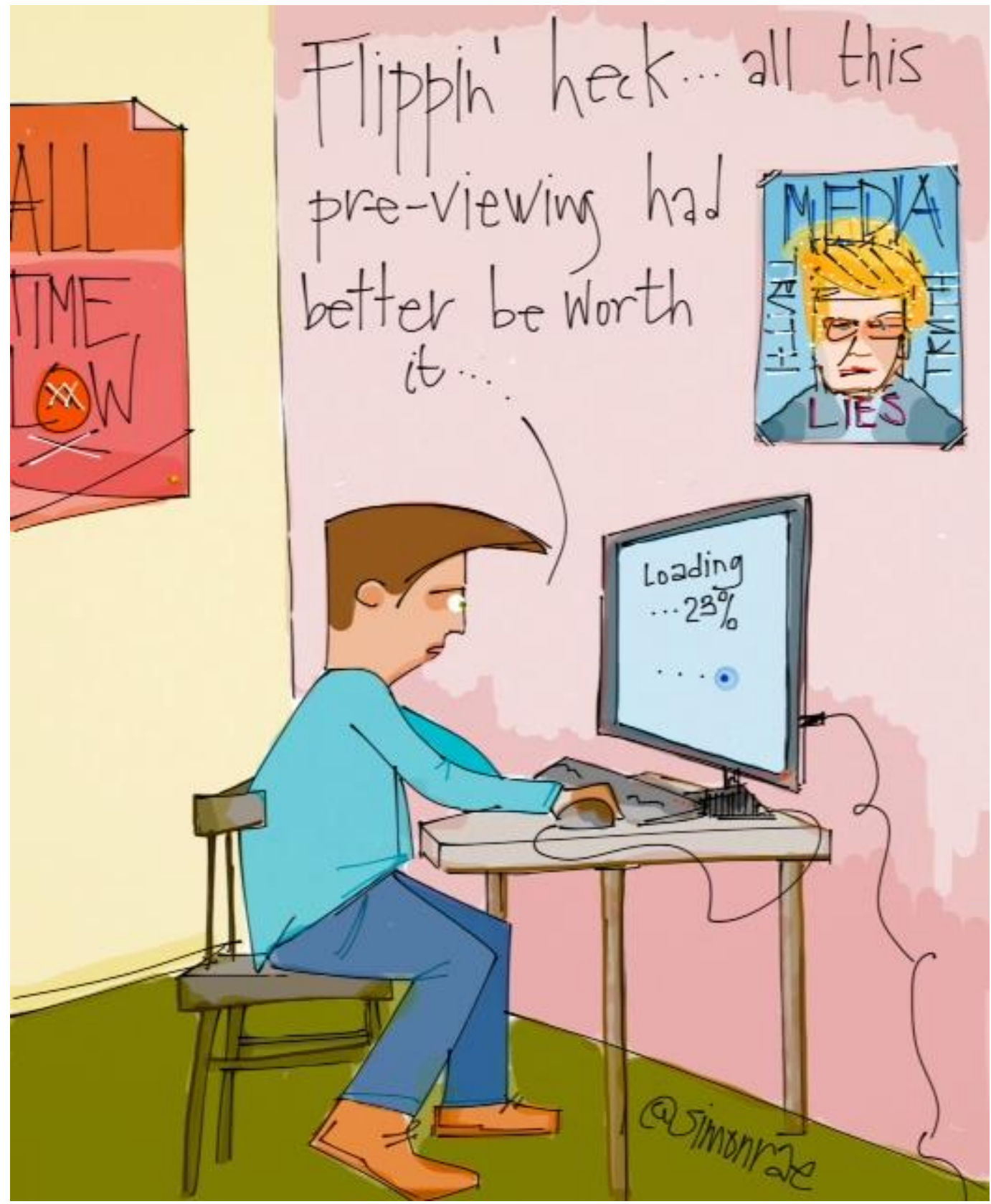

Before you flip the classroom ask whether the material is an essential part of your course. Student engagement in out of class activities should transparently enable a more rewarding face-to-face experience. Lecture theatre activities should lever the space and community to facilitate learning. 


\begin{abstract}
This paper develops a reflective discussion of recent developments of active learning pedagogical approaches, with a focus on class-flipping and peer instruction. We present two case studies based on the experience of the authors in promoting active learning in two-large class undergraduate modules in Introductory Macroeconomics and Descriptive Inorganic Chemistry at the University of East Anglia. Both case-studies are based on a flipping model implemented through by peer instruction. However, the experience of each authors differs in the way the teaching approach was introduced and integrated with additional pedagogies to meet specific needs of the student population, as well as the desired learning outcomes for both modules. In the Introductory Macroeconomics case-study, we discuss how combining peer instruction with a self-assessment component can support the development of students' metacognitive skills. In the Descriptive Inorganic Chemistry case-study, we demonstrate that peer instruction questions can be co-designed in partnership with students to foster engagement and challenge misconceptions. We argue that peer instruction can be used as an effective, scalable, and easily adaptable active learning pedagogy in different many learning environments. Reflecting on our experience, as well as the student voice, our concluding discussion considers: (i) the importance of careful question design, (ii) the role of audience response technologies, as well as (iii) present and future challenges to the promotion of active learning approaches in Higher Education.
\end{abstract}

\title{
1. Introduction
}

In the sciences and social sciences the tradition has been that it is the academic who provides the content in large lectures and that forging understanding is the responsibility of the independent learner. However, there has always been an alternative model in our Universities. For a student taking an English literature degree, the typical pattern is that they would read a text in advance and discuss it in a seminar. Thus, much of the assimilation of content and preliminary consideration is done in advance of the contact time and the seminar can be guided by the academic to construct deep insight.

So-called flipped learning may have been popularised in recent years but there is no sense in which it is a new development (Seery, 2015; Lancaster 2014,16). Careful perusal of the literature reveals many instances of discipline education researchers reporting studies in which materials were provided in advance of lectures. The term inverted classroom was used nearly twenty years ago (Lage et al., 2000) to describe the use of multimedia to present information before lectures to Economic students. In Lage's case the rationale was a questionable belief in catering to the highly contested notion of learning styles. Flipped learning is better justified as enabling active learning for all. The closest we have to a formal definition is: "Flipped Learning is a pedagogical approach in which direct instruction moves from the group learning space to the individual learning space, and the resulting group space is transformed into a dynamic, interactive learning environment where the educator guides students as they apply concepts and engage creatively in the subject matter." (Flipped Learning Network Hub, 2014).

Flipped learning is a broadly defined set of practices. We believe that the critical aspect is making the time for dynamic, interactive engagement with conceptual aspects of our disciplines. How, and crucially, when we go about flipping is discussed in the case studies below. The merits of flipping are debatable. It is not a panacea. Our concern is that it is sometimes employed to avoid taking hard decisions about the value of parts of a course. What is no longer in question is the value of active learning. A recent meta-study of active learning in science, engineering and mathematics showed a $6 \%$ average increase in student assessment results and a substantial reduction in the number of students failing. Indeed, these pedagogical approaches appear to benefit weaker students disproportionately (Freeman et al., 2014). 
Active learning encompasses a raft of pedagogical approaches in the lecture theatre. While often associated with learning technologies, success is invariably dependent on pedagogy, not technology. The advantages of the technology include that it enables the engagement of the whole class, regardless of their cultural or personal inhibitions. The objective is to avoid the classical lecture scenario whereby interaction is restricted to a small subset of students who consistently answer the lecturer's questions.

The reminder of this article is organised in six sections. In Section 2 we describe the features of peer instruction, an active learning pedagogy widely used at the University of East Anglia (UEA), which makes use of class flipping practices. Section 3 and Section 4 present two case studies, describing the experience of the authors in teaching large-class modules in Introductory Macroeconomics and Descriptive Inorganic Chemistry. Section 5 discusses our pedagogical experiences, and Section 6 concludes.

\section{Peer instruction}

We assert that active learning is about more than allocating tasks across group and individual learning spaces. Active learning is about encouraging students to think. Approaches such as Team Based Learning and Problem Based Learning can be very effective. However, they can be difficult to implement in traditional teaching spaces and can require additional facilitators. Peer instruction is an effective, scalable active learning pedagogy ideally suited for a pragmatic transition from traditional lecturing towards an engaging constructive approach (Mazur, 1997).

In peer instruction a multiple choice question is posed to test conceptual understanding. A student should not be able to answer simply by recalling the answer. The lead academic will then poll the class. Every student is encouraged to commit to an answer regardless of their level of confidence and thus invest in the topic. Rather than simply reveal the distribution and explain the correct answer, the class leader will invite students to discuss the question with their peers. The students are then invited to vote again. At this point the results to both polls are revealed. There is normally a substantial shift in the distribution, favouring the correct answer. The lecturer will then lead a discussion in which the valid explanation for the correct answer is developed. For this pedagogical approach to work the question needs to be pitched at the right level. Too easy and all the students will get it right first time around and no learning takes place. Too hard and no student can explain what the correct answer should be and conceptual understanding does not propagate through the class. Mazur refers to questions occupying the sweet spot, while we use the expression Goldilock's zone after the eponymous fairy tale character who liked things 'just right'. Ideally each question is an opportunity for a significant proportion of the class to construct new conceptual understanding through peer discussion.

If the question proves to be too easy for the cohort, which is $80 \%$ are right in the first round, then we would move immediately to the academic explanation and on to the next question. If the question proves too hard, that is less than $30 \%$ are initially correct then further instruction, a conceptual hint, is required before moving to discussion. It is incredibly rewarding to observe peer instruction move a class towards the correct answer through social construction of insight. In the event that the movement is not at the desired level further guidance, stopping well short of the answer will be provided before another round of discussion.

The following sections develop two case-studies that make use of peer instruction through class flipping.

\section{Case-study A: Introductory Macroeconomics at the University of East Anglia}


Introductory Macroeconomics is large-class module that constitutes one of the pillars of the core teaching provision for Economics students at UEA. The module has been traditionally structured in: 2 hours' lectures per week, with the addition of 8 seminars ( 1 hour each) and 8 workshops ( 2 hours each), taking place every fortnight from Week 4 of each semester.

As very common in large-class modules in Economics, seminars are used to promote small-group collaborative-learning, inviting students to discuss the solutions of pre-assigned problem sets. Workshops, instead, are organised as large-class events, where students are confronted with questions never seen before. Lack of instructor's guidance and one-to-one support, as well as the expectation that students develop problem-solving skills, and expand their knowledge directly in the classroom, classify workshops as true moments of active learning through class flipping. The instructor's intervention is strictly limited, while students are challenged to take responsibility and ownership of their learning during contact hours. In this learning environment, we also decided to experiment with the introduction of an additional pedagogical component, aimed at training students to develop their self-assessment skills (Aricò, 2015).

All Introductory Macroeconomics students are endowed with a personal audience response handset (clicker), which they retain for the whole duration of the module. This approach allows the module convener to interact and engage with the class, track individual performances and class performances, deliver timely feedback, and derive learning analytics to adjust teaching in real time.

\subsection{Workshop design}

As soon as each workshop session begins, students receive a sheet reporting: a set of multiple choice questions (MCQs), and (ii) a set of open-ended problem-based questions. Generally, the number of MCQs varies between 8 and 10, while the number of open ended questions varies between 1 and 4 . The MCQs are characterised by 4 possible choices each. This design allows to actively engage students for 2 hours. The facilitator oversees the progress of the session, but the commitment is to let the students to regulate the pace, according to their needs. The teaching algorithm progresses as follows:

1. Students are invited to give an answer to the first $M C Q$, autonomously and without consulting with each other. No solution is discussed at this stage.

2. Students are asked to self-assess their performance, ranking their confidence and mastery of skills on a 4-point Likert-scale.

3. Students are encouraged to share and discuss their answer to the first question, and to give a second and final answer the same question, after the discussion has concluded.

4. The distribution of answers is revealed and the facilitator points the students to the correct answer, explaining the reason for this. Students are invited to ask any clarification question.

5. Finally, students re-iterate self-assessment of their mastery of skills, before the algorithm is repeated for the next MCQ.

During peer-instruction moments, students are entirely in control of their learning, and selfregulate the discussion. They can consult notes, discuss questions in small groups, and compare across different groups. The time needed by students to discuss questions is variable, and the facilitator has to develop some skills, as well as following common sense and intuition, to support the students at pacing their work. A sign that the class is prepared to wrap up the discussion could be: a change in the intensity of the discussion, which is generally signalled by higher or lower background noise caused by students talking to each other. Evidently, students that find MCQs relatively easy to answer, will complete their discussion task earlier. To keep everybody engaged, these students are encouraged to invest time addressing the second part of the problem set, which is based on open-ended questions. Solutions to this second set of questions are covered at the end of the workshop, if time is left. Solutions to the whole problem set are shared online through the VLE after the session has concluded. 
The configuration of teaching space where peer-instruction sessions are held has a strong impact on the student dynamics. Ideally, we wish we could allow students to maximise their interaction, walking freely around the classroom to interface with multiple peers. Due to timetabling constraints, and a large cohort of workshop participants, this is difficult to achieve, and we guess that many other institutions share the same problem. Given that the sitting allocation of students has to be reasonably static during each session, we decided to allow students maximum freedom. We often notice the formation of stable working partnership as study-buddies always tend to sit together, and even in the same place within the teaching space. We believe that nurturing student collaborations that can continue beyond workshops is an important achievement per se, which carries implications for the development of students' study skills and study strategies that go beyond the specific learning objectives of each session.

\subsection{Using multiple choice questions}

Facilitating formative and summative assessment through MCQs most certainly sound like an appealing option, especially when teaching large-class modules. MCQ-based assessment enables facilitators to provide quick feedback to students, and to devise very simple and ready to use metrics to gauge the temperature in the classroom. However, designing engaging and effective MCQs, which maximise student learning, and make good use of contact time with the students, it is not a trivial matter. We suggest that MCQ design should be guided by two main principles: (i) placing questions within the Goldilock's zone, and (ii) maximising learning outcomes. As we argued in Section 2, it is imperative that MCQs are in a sweet spot or Goldilock's zone: presenting problems that are neither too difficult to solve, nor too trivial to address. Both extremes would render peer instruction discussions sterile. Since we have started flipping our Macroeconomics workshops, we have been engaged in a process of constant revision of our question bank, with the aim of bringing all our questions within the Goldilock's zone. This process has been informed by student responses: a very low proportion of correct responses, which does not improve after peer instruction, implies that many students do not master the skills necessary to tackle the problem they have been presented. On the opposite, very high proportions of correct responses at the beginning of the teaching algorithm, indicate that peer instruction is not going to display a significant learning impact on students. Data on student self-assessment were also useful to reviewing MCQs, as they provided us with a further indication of the difficulty perceived by students.

Once the Goldilock's zone is reached, careful pedagogical design should also aim at maximising learning outcomes, challenging students to do more than simply recalling or understanding concepts. Following Bloom's model (Bloom, 1956; Marzano and Kendall, 2007), we argue that effective MCQs should also train students to apply and appraise such concepts in different scenarios. We present two examples:

Which School of Thought claims that financial assets and money are not good substitutes?
A. The Keynesian School
B. The Monetarist School
C. The Schumpeterian School
D. None of the above.

Fig. 1. MCQ Example 1 
Consider the policy debate between Keynesians and Monetarists. According to the Monetarist formulation of the IS-LM model, expansionary fiscal policy is than expansionary monetary policy at increasing equilibrium income, and it generates a relatively crowding-out effect:
A. more effective; weaker
B. less effective; weaker
C. more effective; stronger
D. less effective; stronger.

Fig. 2. MCQ Example 2

Evidently, Example 1 ranks rather low on the Bloom's Taxonomy model, as it requires students to merely recall assumptions belonging to different schools of thought. In Example 2, the question challenges students to: (i) master the general principles of the IS-LM model, (ii) recall how the assumptions of different schools of thought apply to the IS-LM model, (iii) recall, understand, and visualise the concept of crowding-out on the IS-LM diagram, (iv) make use of the IS-LM model to compare the effects of fiscal and monetary policy, and ( $v$ ) evaluate alternative demand-management policies.

\subsection{Enhancing self-assessment skills and augmenting learning}

The introduction of the self-assessment component (Stage 2 and Stage 5 of our teaching algorithm), is our original addition to the peer instruction pedagogy. The ability to self-assess represents an important meta-cognitive skill for students who embark in graduate studies (Nicol and Macfarlane-Dick, 2006).

In our approach, the development of self-assessment skills is not placed in a vacuum, as it is embedded in the experiential learning process that unravels through our teaching algorithm. To this extent, our self-assessment addition aligns peer instruction to Kolb's experiential learning model (Kolb, 1984), as students can benefit from a moment of 'reflective observation', appraising their level of knowledge and skills, prior to engaging in discussion with their classmates. Empirical evidence collected over the period 2012-2017 shows that this addition is very effective. Measuring the association of correct/incorrect responses with student self-assessment statements, we can demonstrate that, session after session, the whole class displays good self-assessment performances. This result is not trivial, as the dominant literature on self-assessment claims that low-performers are generally unable to correctly assess their abilities (Kruger and Dunning, 1999; Dunning et al., 2003). This finding is in line with the assumption that our pedagogy empowers low-performers with the ability to self-assess correctly, which is another argument in favour of embracing an active learning approach to teaching.

To appraise the effectiveness of peer instruction, we consider the class learning gain, defined as the difference between the proportion of correct responses to formative questions before and after class discussion. We find that, the size of the class learning gain is negatively related to the proportion of correct responses before peer instruction. In other words, when the initial proportion of correct responses is low, peer instruction generates a larger learning gain. Even in this case, we can argue that our pedagogy supports low-performers, generating a 'catch-up effect' in the classroom, and allowing 
most students to converge to the same level of skills and knowledge by the end of each iteration of our teaching algorithm.

\subsection{Economics student evaluations}

To assess how students perceive the peer instruction pedagogy adopted in the Introductory Macroeconomics module, we experimented with two different approaches. Prior to being exposed to peer instruction, students were briefly explained how workshops would operate during the module's introductory lecture. At the end of the lecture, students were asked to express their agreement with the statement: "Peer-instruction' sessions (students teaching each other) are more effective than lectures (teacher teaching students)". Then, at the end of each workshop, students would be asked to express agreement with the statement: "I have learnt more Economics by discussing answers with my classmates". While only about $40 \%$ of students agreed with the first statement, more than $80 \%$ of students agreed with the second statement (average across 8 workshops). This indicates that students can be initially suspicious of peer instruction, but, once exposed to the pedagogy, they recognise its effectiveness.

Following a second approach, at the end of the module students were asked: "What is the component of the Introductory Macroeconomics module which had the strongest impact on your learning?". $51 \%$ of students identified workshops as the most effective component, with only $20 \%$ indicating seminars, and the remaining $16 \%$ indicating either lectures, support sessions, or online material (13\% did not answer). While the figures reported pertain the 2014-15 student cohort, we observed a consistent pattern across the years. Acknowledging variation in students' preferred way to learn, we regard these results as supportive of the active learning pedagogy we use. Nevertheless, it is evident that students become acquainted with a way of learning that they had never encountered before; the transition does not necessarily suit everybody's taste, or not at the same point in time at least.

\section{Case-study B: Descriptive Inorganic Chemistry}

Traditionally main group Inorganic Chemistry is taught systematically by working across the periodic table from left to right describing the characteristics of the elements one group (vertical column) at a time. Although the periodic table is laid out to capture intrinsic periodicity (repeating patterns of reactivity) from the student's perspective such a course can appear as a litany of unconnected items to memorise. The lecture becomes the vehicle for transcribing this list from the notes of the lecturer to those of the student. Learning comes much later and is reserved for those parts corresponding to model answers for the question predicted to come up in the examination. There is a danger that students become more focused on the periodicity of a particular question type than the properties of the periodic table. Our ambition was to recast the course not as a collection of content requiring last minute rote memorisation but as a conceptual framework conducive to enduring understanding.

\subsection{Better utilisation of lecture capture}

Our lecture flipping has been facilitated by an archive of screencast lectures captured in the 20102011 academic year. The fundamentals of Inorganic Chemistry, like those of macroeconomics, are well established and do not radically change from year-to-year. It is revealing to observe the pattern of usage of lecture capture archives. Sarsfield and Conway have observed marked differences between the students of different disciplines. Mathematics students would typically view lecture recordings 
within days of the lecture and not to return to them again. Whereas bioscience students would not view the recordings until examinations were imminent. Our experience in Chemistry was that practice was closer to the bioscience model (Read and Lancaster, 2013). It is tempting to equate this behaviour with the perception of material as being conceptual and enduring, as opposed to content to be crammed into short term memory and only required to pass an examination.

By 2012, we had seized upon lecture flipping as a more positive potential application of lecture capture than enabling last-minute binge recapitulation. Audience response handsets (clickers) are routinely used in many Higher Education settings to poll students.

The initial reception of flipping by our students was largely positive. The student evaluation metrics, recorded against a Likert scale, showed no significant difference from the year before lecture flipping was introduced (Read and Lancaster, 2013). On reflection, these initial questions were poor. They tended to focus on assessing whether the students had done the required preparation. The turning point for our practice was a meeting with Ross Galloway, a Physicist from Edinburgh, who introduced peer instruction (Mazur, 1997).

In the 2015-16 academic year the contact hours of the Descriptive Inorganic Chemistry course were delivered entirely in peer instruction mode. Students were encouraged to view screencast recordings in advance of the contact hours but only instructed to ensure that they did so where the material was not part of their university preparation assessments (which, for the vast majority of this cohort, would be English A Levels).

Students would typically answer 8-10 peer instruction questions in a 50 minute slot. The questions were predominantly prepared by the lead academic with the intention of testing conceptual understanding. Each question was classified by an undergraduate co-worker according to Bloom's Taxonomy. Most were agreed to require conceptual understanding, while a few also required the application of that understanding (Lancaster, 2016).

The peer instruction cycle described above presupposes that the initial distribution of answers is in the Goldilock's zone. We will typically move on once $80 \%$ of the class are correct, further guidance and discussion is possible but there is inevitably a diminishing return. The student with an embedded belief level misconception will not relinquish that quickly.

\subsection{Co-creating peer instruction questions in partnership with the students}

Where our practise diverges from the Mazur model is in co-authorship with our students. Years of experience will generally provide a good indication of where misconceptions and cognitive challenges are present. We can test for these through distractors in our MCQs. However, if we are unaware of a misconception, it can persist without confrontation through a course. To counter this, we will provide the stem of a MCQ and invite our students to provide possible answers. In practice this can be done using the free text option of audience response technologies. The polling and subsequent peer instruction is then on students' own answers.

The Peerwise platform takes this process a step further and provides an environment for students to construct their own questions, answer other students' questions and comment upon the questions (Bates and Galloway, 2014). Peerwise can provide a degree of validation and reliability testing to questions that, given appropriate ethical consideration, we can subsequently use in peer instruction.

\subsection{Chemistry student evaluation}

Table 1 presents a selection of student comments on the specific case study described here, which is by far the most intense flipped course we have yet delivered.

\section{Table 1:}


Student comments on a fully flipped Chemistry course

Feedback theme Illustrative quote

Appreciation for interactivity

I really really loved the interactive lectures, they made me more engaged and I believe I learnt more in this style of teaching.

Requirement and outright failure to prepare in advance

I didn't really like the format of the lectures. Having to watch the screen cast first and then spend the entire lecture on response ware answering questions did not work that well for me. I think it would have been better to at least do a brief lecture on the current topic, leaving room for questions and extra explanation if needed along the way, before then completing the session with maybe 20 minutes of questions.

The Screencasts are essential to go through before the lectures, but this is a good thing. The format was different and refreshing to other lecture formats, but wouldn't work as well for other modules such as biology modules.

Lack of confidence in the pedagogy

The reliance on responseware (audience response) before teaching the content made it hard to truly understand a lot of the material outside of a test/exam mindset. Additionally the lack of 'traditional anecdotal style lecturing' made creating comprehensive notes more difficult. I personally do not believe that screencasts are an equivalent worthy of replacement for traditional lectures all the time.

Enthusiastic and engaging, would have preferred less of the pre-lecture screencasts and more of this material being taught in the lectures rather than the 'big scale tutorial' type set up. Maybe each lecture could be accompanied by a set of these questions, as they were useful an I understood the merit of completing them.

Less focus on flipped learning thing. When received feedback and adapted a bit worked better. too much reliance on understanding material if purely ask questions so some coverage of material by lecturer needed.

\section{Propagating Active Learning}

Given the overwhelming evidence for the benefits of active learning, and the positive reception by the students who engage, it is interesting to reflect why such practices have not swept through Higher Education. We recognise two major obstacles, the entrenched attitudes of colleagues and the prior experience of our students.

There are colleagues who regard active learning as a passing fashion and who seek to resist any innovation in teaching practice (French and Kennedy, 2016). A familiar refrain one hears from colleagues is "lecturing worked for me". Even if we accept these essentially unsubstantiated assertions, it is worth reflecting that future-academics make up less than $0.2 \%$ of the average undergraduate class (Royal Society, 2010). Equally common is, "Ah, but my lectures are inspiring and intellectually stimulating". Perhaps, but here we note data gathered by investigators studying peer 
instruction classes: for a typical peer instruction session, it is still the case that approximately half of the student's time is occupied in (passively) listening to the lead academic (Wood et al., 2016). If a carefully crafted flipped session contains so much listening, what proportion for the lecturer who inserts the occasional off-the-cuff query? How can that lecturer be confident all their students are thinking about an answer if they reject technology?

In the UK, the typical entry route to a University education is through A Levels. Top Universities require the very highest grades. Students are therefore motivated by assessment outcomes. A Level teachers are rewarded for the success of their students. School league tables rank schools on the grades their students achieve. Schools become examination factories. This process creates inflationary pressure on grades. Governments respond to the inevitable accusations of dumbing down by adding to the syllabus and making the questions more convoluted. Teachers respond by focusing even more on examination rehearsal. Students arrive at University having been selected on their ability to pass examinations. Examinations that have become so challenging that the only response is a superficial memorisation of model answers, crammed immediately before and forgotten within days. There is no time for a conceptual approach to learning. Indeed, by the time they arrive at University, students have forgotten most of what they thought they knew (Jones et al., 2015).

\subsection{Student evaluations and student partnership}

While it is notoriously difficult to determine learning gain, it is relatively easy to measure student teaching perceptions. As a consequence, student satisfaction surveys have acquired pre-eminence in determinations of teaching competence and indeed excellence that they are ill suited for. Evaluation methods adopted in Introductory Macroeconomics are deliberately targeted to assess the class flipping and peer instruction component of the module, but these constitute ad hoc tools, which do not conform to module evaluation standards. This can generate tension between institutional evaluation methods and the need to move towards more imaginative and effective ways to listen to the student voice. We advocate that designing and implementing new pedagogies should also involve a review of evaluation methods, creating a stronger partnership with the student body.

When we first encounter students, their recent experience of teaching consists of review of examination paper model answers. Thus, we enter a frank dialogue with our students about why we are choosing to teach through peer instruction and not simply giving entertaining lectures to present content. The vast majority of students recognise the benefits and are highly complementary (Read and Lancaster, 2012).

The comments presented Table 1 include somewhat less positive student comments that illustrate why a student might not approve of our approach. What is striking are the post-truth-like assertions that students know best what constitutes good teaching method. These are critiques not of competency or execution but of pedagogy. As academics, we have to balance effectiveness with popularity. These are not mutually exclusive, but they are certainly not the same thing. There is a whole raft of different reasons not to use module evaluation data in promotion decisions. Encouraging pedagogical change is another. Not redressing the balance between rote memorisation and conceptual understanding in the learning experience of our students might not impact upon our key performance indicators, but it does undervalue Higher Education. We urgently need to start taking a longer-term view of the resources we invest in our education system. If the need to please all students, and a focus on dubious metrics, are obstacles to the adoption of active learning, the corollary is that student endorsement is a powerful motivator for change. Reading comments like those in Table 1, and reviewing the evidence provided by learning analytics on the Introductory Macroeconomics module, has encouraged many of our colleagues to experiment with active learning pedagogies for themselves. Peer instruction is for the confident academic prepared to relinquish control and dynamically respond to the needs of their students. Approaches such as Team Based Learning present many of the same cognitive challenges to our students, but in a much more controlled environment. 
The case studies presented suggest tangible ways to develop and implement effective active learning approaches. These included: developing students' self-assessment skills, involving students in a dialogue about the pedagogy and its learning analytics, as well as engaging them in co-production of the teaching material, crafting their own questions to be discussed over peer instruction.

\subsection{The role of learning technologies in facilitating active learning}

In both the case studies presented in this article, audience response handsets and peerinteraction platforms played a fundamental role in facilitating a dialogue between students and teachers, as well as students amongst themselves. There is a vast literature proving the effectiveness of these learning technologies at engaging students and creating an environment where response anonymity facilitates class participation (e.g. Hoekstra and Mollborn, 2012; Masikunas et al., 2007). There is weaker evidence on the effectiveness of learning technologies at improving student performance (e.g. Rao and DiCarlo, 2000; Anthis, 2011; Elicker and McConnell, 2011). We regard this second result as unsurprising, as it is good pedagogical use of technologies, rather than technologies alone, which can effectively enhance student learning and student performance (Nielsen, et al., 2013).

Aside from engagement and anonymity, the use of audience response handsets in peer instruction encourages students to commit to an answer, hence actively engaging in the discussion that follows. By displaying the outcome of question polling, audience response platforms offer immediate feedback to students, developing their ability to appraise their skills and eliciting selfregulatory behaviours. Ultimately, they provide the class with the evidence that peer instruction is an effective method to learn. As most audience response platforms allow the teacher to display the distribution of answers before and after peer instruction, students can see with their own eyes that engaging in discussion with their peers positively influences their responses towards the correct answer. When this pattern does not occur, teachers and students can address misconceptions immediately and effectively, as they arise. Even where the peer instruction process results in a shift towards the correct answer, it is possible that this occurs for the wrong reasons. Therefore, the concluding academic explanation remains an important part of the overall process (Mazur 1997; Wood, 2014).

The process by which peer instruction affects learning has been analysed through the lens of Hammer's resources model (Hammer 1996, 2005). The peer-to-peer discussions are critical in getting the students to think (activating their cognitive resources), thus enabling them to see the problems in a new light (Wood, 2014).

Making use of learning technologies has also the advantage of generating large basis of data, which can be analysed to uncover learning patterns, help students who are experiencing specific difficulties, and support the teacher in a process of continuous revision of her teaching material.

\section{Conclusions}

There is overwhelming evidence that active learning approaches are more effective than passive delivery. This confers a duty on the educator to incorporate these techniques in their teaching. However, teaching through pedagogies such as peer instruction requires considerably more time for a given topic. This should lead to careful reflection on the case for including each component of a course. In many instances, time can be freed for active learning by sacrificing insignificant parts of the syllabus. When content has been cut to the essential, and there is still insufficient time, then flipping provides an answer. There is no single pedagogy for flipping, but the uniting principle is the drive to move the content delivery component out of the classroom and to free contact time for constructivist pedagogies. Where resource constraints require large group teaching in lecture theatre environments, peer instruction is a convenient, effective and scalable solution. Coupling peer instruction with self- 
assessment and co-authoring approaches can see improvements in conceptual understanding mirrored by confidence.

\section{Declaration of interest}

Both authors are international distinguished educators for Turning Technologies ${ }^{\mathrm{TM}}$ and receive material support in the form of audience response handsets and licenses.

\section{Acknowledgements}

The authors are grateful for the support of The University of East Anglia and the counsel of Neil Ward, Adam Longcroft and Helena Gillespie. The graphical abstract art is by Simon Rae. SJL is grateful to Dennis Cook for discussions on the taxonomy of his peer instruction questions.

\section{References}

Aricò, F.R. (2015). Peer-instruction Unveiled: unlocking the power of Student Response Systems, The Economics Network, http://www.economicsnetwork.ac.uk/showcase/arico_clickers [Accessed 6 May. 2017].

Bates, S. Galloway, R. K. Riise, J. Homer, D. (2014) Assessing the quality of a student-generated question repository In Phys. Rev. ST Phys. Educ. Res, volume 10.

Anthis, K. (2011). Is It the Clicker, or Is It the Question? Untangling the Effects of Student Response System Use. Teaching of Psychology, 38(3), pp.189-193.

Bloom, B. and Krathwohl, D. (1956). Taxonomy of educational objectives. 1st ed. D. McKay, New York.

Dunning, D., Johnson, K., Ehrlinger, J. and Kruger, J. (2003). Why people fail to recognize their own incompetence. Current Directions in Psychological Science, 12(3), pp.83-87.

Elicker, J. and McConnell, N. (2011). Interactive Learning in the Classroom. Teaching of Psychology, 38(3), pp.147-150.

Flipped Learning Network Hub. (2014). Flipped Learning Network Hub. [online] Available at: http://flippedlearning.org/ [Accessed 12 Apr. 2017]. 
Freeman, S., Eddy, S., McDonough, M., Smith, M., Okoroafor, N., Jordt, H. and Wenderoth, M. (2014). Active learning increases student performance in science, engineering, and mathematics. Proceedings of the National Academy of Sciences, 111(23), pp.8410-8415.

French, S. and Kennedy, G. (2017). Reassessing the value of university lectures. Teaching in Higher Education, pp.1-16.

Hammer, D. (1996). More than misconceptions: Multiple perspectives on student knowledge and reasoning, and an appropriate role for education research. American Journal of Physics, 64(10), pp.1316-1325.

D. Hammer, A. Elby, R. E. Scherr, and E. F. Redish, in Resources, Framing, and Transfer, edited by J. P. Mestre (Information Age Publishing Inc., Charlotte, NC, 2005), pp. 89-120.

Hoekstra, A. and Mollborn, S. (2012). How clicker use facilitates existing pedagogical practices in higher education: data from interdisciplinary research on student response systems. Learning, Media and Technology, 37(3), pp.303-320.

Jones, H. Black, B. Green, J. Langton, P., Rutherford, S., Scott, J. and Brown, S. (2015) Indications of Knowledge Retention in the Transition to Higher Education J. Biol. Educ. 49, 261-273

Kolb, D. (1984). Experiential learning: experience as the source of learning and development. 1st ed. Englewood Cliffs, NJ: Prentice Hall.

Kruger, J. and Dunning, D. (1999). Unskilled and unaware of it: How difficulties in recognizing one's own incompetence lead to inflated self-assessments. Journal of Personality and Social Psychology, 77(6), pp.1121-1134.

Lage, M., Platt, G. and Treglia, M. (2000). Inverting the Classroom: A Gateway to Creating an Inclusive Learning Environment. The Journal of Economic Education, 31(1), p.30.

Lancaster, S. J. (2014) The Flipped Lecture, New Directions in the Teaching of Physical Sciences https://journals.le.ac.uk/ojs1/index.php/new-directions/article/view/484/482 [Accessed 8 May 2017]. 
Lancaster, S. J. (2016) Engaging Chemistry Students. Higher Education Academy https://www.heacademy.ac.uk/engaging-chemistry-students [Accessed 8 May 2017].

Marzano, R. and Kendall, J. (2007). The new taxonomy of educational objectives. 1st ed. Thousand Oaks, CA: Corwin Press.

Masikunas, G., Panayiotidis, A. and Burke, L. (2007). The use of electronic voting systems in lectures within business and marketing: a case study of their impact on student learning. Research in Learning Technology, 15(1).

Mazur, E. (1997). Peer instruction: a user's manual. 1st ed. Upper Saddle River: Prentice Hall.

Nicol, D. and Macfarlane-Dick, D. (2006). Formative assessment and self-regulated learning: a model and seven principles of good feedback practice. Studies in Higher Education, 31(2), pp.199-218.

Nielsen, K., Hansen, G. and Stav, J. (2013). Teaching with student response systems (SRS): teachercentric aspects that can negatively affect students' experience of using SRS. Research in Learning Technology, 21(1), p.18989.

Rao, S. and DiCarlo, S. (2000). Peer instruction improves performance on quizzes. Advances in Physiology Education, 24, pp.51-55.

Read, D. and Lancaster, S. (2012). Unlocking video: 24/7 learning for the iPod generation. Education in Chemistry, 49(4), pp.13-16.

Read, D. and Lancaster, S. (2013). Flipping lectures and inverting the classroom. Education in Chemistry, [online] (September). Available at: http://www.rsc.org/eic/2013/10/flippedclassroom-inverting-lectures [Accessed 6 May 2017].

Royal Society (2010). The Scientific Century: securing our future prosperity. 1st ed. [ebook] London: RS Policy document 02/10, DES1768, pp.1-75. Available at: https://royalsociety.org/ /media/Royal_Society_Content/policy/publications/2010/429497012 6.pdf [Accessed 6 May 2017]. 
Sarsfield, M. and Conway, J. What can we learn from learning analytics: A case study based on an analysis of student use of video recordings https://www.slideshare.net/msars/what-can-welearn-from-learning-analytics-66210275 [accessed 05.05.17]

Seery, M. (2015). Flipped learning in higher education chemistry: emerging trends and potential directions. Chem. Educ. Res. Pract., 16(4), pp.758-768.

Wood, A., Galloway, R., Hardy, J. and Sinclair, C. (2014). Analyzing learning during Peer Instruction dialogues: A resource activation framework. Physical Review Special Topics - Physics Education Research, 10(2). 